\title{
Special Thanks
}

The research project Revitalizing Health for All:Learning from Comprehensive Primary Health Care Experiences, which enabled the teams contributing to the book to conduct their research, was kindly supported by the Global Health Research Initiative, a collaborative research funding partnership of the Canadian Institutes of Health Research, the Canadian International Development Agency, Health Canada, the International Development Research Centre (IDRC), and the Public Health Agency of Canada, through IDRC Grant No. 103460-041. Smaller additional grants supported the project, notably a grant from the World Health Organization's Alliance for Health Policy and Systems Research to promote capacity development for health policy and systems research, and IDRC Grant No. 103460-084 to introduce knowledge transfer and exchange as well as outcomes mapping to the project's teams. We are also grateful to the International Development Research Centre for their grant (107108-00020703-025) to collate and publish this volume on the research findings of the project and the individual teams.

We would like to acknowledge that the initial concept for this project was developed in the first International People's Health University, a training course on the political economy of health and primary health care, held in association with the Second People's Health Assembly of the People's Health Movement (www.phmovement.org) in Cuenca, Ecuador, in 2005. Particular thanks go to Francoise Barten, Fran Baum, Rakhal Gaitonde, Maija Kagis, David Legge, Thelma Narayan, and Claudio Schuftan.

We would also like to express our sincere appreciation to Shirley Sarfo, Margaret Frère, Mary Holshausen, and Elsa Michel at the University of Ottawa for their assistance in bringing this book to print. In 
addition, we wish to thank Nola Haddadian at IDRC for her editing assistance.

Finally, the editors on behalf of the contributors dedicate this book to the memories of Gwendolyn ("Lyn") Lusi, deceased 17 March 2012, and Dr. Christa ("Victoria") Baatz, deceased 17 April 2015. Ms. Lusi (Chapter 4) cofounded a charity providing medical and social services in Goma, DRC, and committed herself to supporting women victims of violent rape. Dr. Baatz played a major and inspiring role in the development of the comprehensive primary health care system in Guarjila, El Salvador, described in Chapter 15.

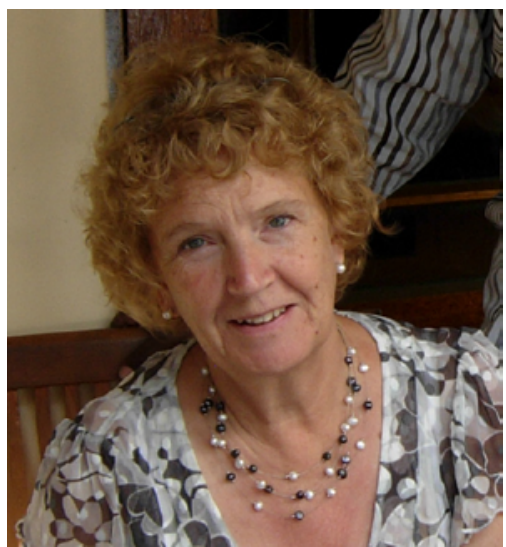

Lyn Lusi, cofounder of HEAL Africa, Democratic Republic of Congo

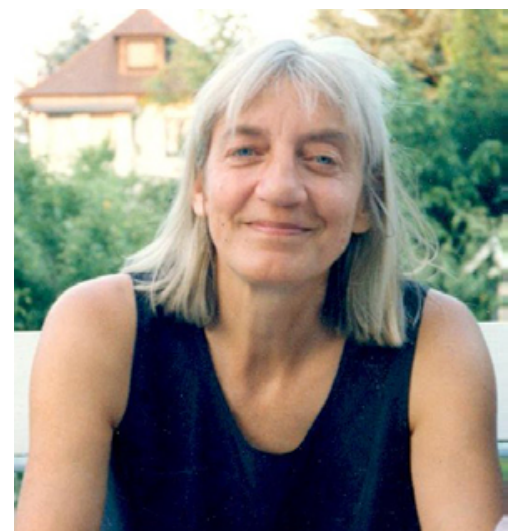

Christa Baatz, champion of CPHC in Guarjila, El Salvador 


\section{REVITALIZING HEALTH FOR ALL}

Case Studies of the Struggle for

Comprehensive Primary Health Care 
This page intentionally left blank 